\title{
STRATEGI MARKETING PUBLIC RELATIONS ASHRAM GANDHI PURI SEVAGRAM DALAM MEMPERTAHANKAN CITRA POSITIF ORGANISASI
}

\author{
I Wayan Sari Dika ${ }^{\mathrm{a}, 1}$ \\ I Gede Sutarya ${ }^{\mathrm{a}}$ \\ I Ketut Wardana Yasa ${ }^{a}$
}

a Universitas Hindu Negeri I Gusti Bagus Sugriwa Denpasar

${ }^{1}$ Corresponding Author, email: wayandika14@gmail.com (Dika)

\section{ARTICLE INFO}

Article history:

Received: 29-01-2021

Revised: 20-02-2021

Accepted: 17-03-2021

Published: 31-03-2021

\section{Keywords:}

Strategy,

Marketing Public

Relations, Image,

Gandhi Puri

Sevagram Ashram
ABSTRACT

The Gandhi Puri Sevagram Ashram, as an organization engaged in the spiritual and educational fields, was reported negatively, causing its image to deteriorate. This makes people familiar with the Gandhi Puri Sevagram Ashram from the negative side, but when the news was slowly stopped by the Marketing Public Relations of the Gandhi Puri Sevagram Ashram by always providing information about activities at the ashram to the public through newspapers and social media. This research focuses on the discussion of (1) Public perceptions of the Gandhi Puri Sevagram Ashram (2) Marketing public relations strategy of Gandhi Puri Sevagram Ashram in maintaining a positive image of the organization (3) Implications of public relations marketing strategy for the image building of Gandhi Puri Sevagram Ashram. The theory used in analyzing are: Consumer Behavior Theory, and Integrated Marketing Communication Theory. This research uses observation methods, in-depth interviews, questionnaires, document studies, and documentation studies. This research finds first, people's perceptions about the Gandhi Puri Sevagram Ashram based on the results of questionnaire data taken from 100 respondents via google form using several predetermined indicators, obtained the average respondent's answer data reached 4.15 so it is classified as good criteria. Secondly, Ashram Gandhi Puri Sevagram's marketing strategy of public relations in maintaining a positive image of the organization has been carried out using a combination of marketing communications through advertising, events and community networks. Third, the implications of the marketing public relations strategy for building the image of the Gandhi Puri Sevagram Ashram can make the ashram better known, the ashram gets the opportunity to serve the community in various fields and the ashram gets a lot of scholarships and groceries from donors.

\section{PENDAHULUAN}

Agama Hindu adalah salah satu agama yang memiliki banyak pola pendidikan dimana salah satunya yaitu ashram. Ashram sendiri merupakan tempat dimana untuk melaksanakan aktivitas spiritual keagamaan dengan pola 
tertentu dan terdapat aturan Guru dan Sisya yang baku. Ashram adalah wahana untuk pembelajaran dalam berbagai bidang kehidupan yang sifatnya non formal. Disaat ini sudah ada banyak ashram yang berdiri namun sangat sulit untuk selalu eksis dimasyarakat karena sering mendapat tudingan miring dari oknum yang tidak bertanggung jawab yang mengatakan bahwa pendidikan di ashram sudah seperti keindia-indian sehingga cenderung menimbulkan citra yang tidak baik dikalangan masyarakat. Citra yang tidak baik inilah yang perlu diperbaiki oleh setiap ashram dengan cara melakukan komunikasi yang intens dengan masyarakat untuk itu sangat diperlukan sosok seorang Marketing Public Relations.

Marketing Public Relations merupakan perpaduan (sinergi) antara pelaksanaan program dan strategi pemasaran (marketing strategy implementation) dengan aktivitas program kerja public relations (work program of PR). Marketing Public Relations inilah yang nantinya diharapkan agar dapat mengubah persepsi masyarakat yang awalnya kurang baik terhadap keberadaaan ashram melalui strategi yang telah diterapkan sehingga nantinya akan menimbulkan dampak atau implikasi yang baik sehingga dapat membantu setiap ashram dalam mempertahankan citra positif dikalangan masyarakat melalui strategi-strategi yang telah diterapkan.

Berdasarkan hal tersebut Ashram Gandhi Puri Sevagram menyadari akan pentingnya seorang public relations di dalam organisasinya untuk mengubah tudingantudingan masyarakat dan mengcounter berita-berita negatif yang nantinya akan menerpa ashram. Marketing public relations merupakan sinergi proses public relations dalam kampanye pemasaran sosialisasi program-program yang dibuat oleh Ashram Gandhi Puri Sevagram. Program tersebut merupakan suatu kegiatan yang dapat mendekatkan masyarakat terhadap ashram dengan aksi komunikasi yang dibuat oleh marketing public relations sehingga dapat mempertahankan citra positif ashram di masyarakat. Berdasarkan latar belakang tersebut maka penelitian yang diteliti oleh penulis berjudul "Strategi Marketing Public Relations Ashram Gandhi Puri Sevagram dalam Mempertahankan Citra Positif Organisasi".

\section{METODE PENELITIAN}

Metode yang digunakan dalam penelitian ini adalah pendekatan deskriptif kualitatif yang didukung oleh data kuantitatif berupa angka, karena penelitian ini banyak mengeksplor tentang persesi masyarakat dan strategi marketing public relations Ashram Gandhi Puri Sevagram dalam mempertahankan citra positif organisasi. Selain itu penelitian ini juga bersifat induktif dan hasilnya lebih menekankan makna. Metode pengumpulan data yang digunakan dalam penelitian ini adalah teknik obervasi, wawancara mendalam, kuesioner, studi dokumen dan studi kepustakaan.

\section{HASIL DAN PEMBAHASAN}

\section{Persepsi Masyarakat Terhadap Ashram Gandhi Puri Sevagram}

Pengertian persepsi dari kamus psikologi adalah berasal dari bahasa Inggris, perception yang artinya: persepsi, penglihatan, tanggapan; adalah proses seseorang menjadi sadar akan segala sesuatu dalam lingkungannya melalui indera-indera yang dimilikinya; atau pengetahuan lingkungan yang diperoleh melalui interpretasi data indera (Kartono dan Gulo, 1987).

Persepsi dari setiap orang bisa berbedabeda terhadap suatu objek, sehingga diperlukan 100 sampel yang diambil secara acak melalui google form untuk dapat mengetahui bagaimana persepsi masyarakat terhadap Ashram Gandhi Puri Sevagram. Jumlah responden yang diambil adalah 100 orang responden yang selanjutnya digunakan pada analisis karakteristik untuk mendapatkan gambaran umum mengenai 
responden. Analisis karakteristik responden digunakan untuk memberikan gambaran responden, apakah dengan karakteristik responden yang berbeda-beda mempunyai penilaian yang sama ataukah tidak. Adapun karakteristik responden dikelompokkan atas beberapa kriteria diantaranya kota asal, domisili, umur , jenis kelamin, pekerjaan, dan pendapatan perbulan responden. Kriteria pengambilan data dalam penelitian ini adalah orang-orang yang pernah berkunjung ke Ashram Gandhi Puri Sevagram.

Menurut teori perilaku konsumen dipahami sebagai tindakan yang langsung terlibat dalam mendapatkan, mengkonsumsi, dan menghabiskan produk dan jasa, termasuk proses keputusan yang mendahului dan menyusuli tindakan ini (Setiadi, 2003: 3). Untuk menguji jawaban responden terhadap bagaimana strategi marketing public relation Ashram Gandhi Puri Sevagram, digunakan beberapa indikator yang dapat mewakili jawaban terhadap persepsi masyarakat mengenai hal tersebut antara lain dilihat dari Publikasi, iklan layanan masyarakat, Special Event, Promosi dan Publikasi Program, dan Advetorial (Sponsorship). Hasil dari beberapa indicator tersebut terlampir pada table berikut:

Tabel 1 Hasil Indikator Jawaban Responden

\begin{tabular}{|c|c|c|c|c|c|c|c|}
\hline \multirow[t]{2}{*}{ Pertanyaan } & \multicolumn{5}{|c|}{ Distribusi Jawaban } & \multirow{2}{*}{$\begin{array}{c}\text { Rata- } \\
\text { Rata Skor }\end{array}$} & \multirow[t]{2}{*}{ Kriteria } \\
\hline & SS & $S$ & $\mathrm{CS}$ & TS & STS & & \\
\hline $\begin{array}{l}\text { 1. Public Relations ashram gandi puri dapat } \\
\text { menggambarkan/menginformasikan } \\
\text { tentang adanya Ashram Gandhi Puri } \\
\text { dengan baik }\end{array}$ & 38 & 45 & 11 & 1 & 5 & 4,1 & Baik \\
\hline $\begin{array}{l}\text { 2. Public Relations Ashram Gandhi Puri } \\
\text { telah memiliki cara kerja yang baik } \\
\text { dalam memasarkan/mempromosikan } \\
\text { ashram ganti puri kepada masyarakat }\end{array}$ & 36 & 45 & 12 & 3 & 4 & 4,06 & Baik \\
\hline $\begin{array}{l}\text { 3. Public Relations Ashram Gandhi Puri } \\
\text { telah berhasil menarik perhatian } \\
\text { masyarakat }\end{array}$ & 37 & 44 & 13 & 3 & 3 & 4,09 & Baik \\
\hline $\begin{array}{l}\text { 4. Public Relations Ashram Gandhi Puri } \\
\text { telah melakukan promosi dengan tepat } \\
\text { dan akurat }\end{array}$ & 27 & 48 & 19 & 4 & 2 & 3,94 & Baik \\
\hline $\begin{array}{l}\text { 5. Event yang diadakan oleh Public } \\
\text { Relation Ashram Gandhi Puri } \\
\text { berorientasi pada pembentukan citra } \\
\text { Ashram Gandhi Puri }\end{array}$ & 47 & 34 & 13 & 3 & 3 & 4,19 & Baik \\
\hline $\begin{array}{l}\text { 6. Event yang diadakan oleh Ashram } \\
\text { Gandhi Puri dirancang dengan nuansa } \\
\text { hiburan yang menarik untuk } \\
\text { membangkitkan kesadaran dan minat } \\
\text { masyarakat }\end{array}$ & 45 & 35 & 15 & 3 & 2 & 4,18 & Baik \\
\hline $\begin{array}{l}\text { 7. Terdapat organisasi lain yang } \\
\text { mendukung Ashram Gandhi Puri. }\end{array}$ & 40 & 37 & 17 & 3 & 3 & 4,08 & Baik \\
\hline $\begin{array}{l}\text { 8. Organisasi tersebut secara konsisten } \\
\text { memberikan perhatian berulang kepada } \\
\text { Ashram Gandhi Puri }\end{array}$ & 27 & 52 & 14 & 6 & 1 & 3,98 & Baik \\
\hline Rata-rata skor strategi marketing public relc & & & & & & 4,08 & Baik \\
\hline
\end{tabular}

Berdasarkan tabel di atas didapatkan data bahwa rata rata jawaban responden dalam penelitian ini adalah 4,08 sehingga dapat disimpukan bahwa responden memiliki 
tanggapan yang baik mengenai strategi marketing public relations. Untuk menguji jawaban responden terhadap bagaimana citra Ashram Gandhi Puri Sevagram dimata masyarakat, digunakan beberapa indikator yang dapat mewakili jawaban terhadap persepsi masyarakat mengenai hal tersebut antara lain dilihat dari kepercayaan terhadap organisasi, integritas organisasi dan reputasi organisasi. Hasil tanggapan responden terhadap 3 butir pertanyaan dari indikator citra positif organisasi sebagai berikut :

Tabel 2 Tabel Citra Positif Organisasi

\begin{tabular}{lccccccc}
\hline \multicolumn{1}{c}{ Indikator } & \multicolumn{5}{c}{ Distribusi Jawaban } & \multicolumn{3}{c}{ Rata-Rata } & Kriteria \\
& SS & S & CS & TS & STS & Skor & \\
\hline $\begin{array}{l}\text { 1. Masyarakat memiliki rasa percaya } \\
\text { terhadap Ashram Gandhi Puri }\end{array}$ & 34 & 42 & 17 & 4 & 3 & 4 & Baik \\
$\begin{array}{l}\text { 2. Ashram Gandhi Puri memiliki } \\
\text { integritas yang t }\end{array}$ & 52 & 31 & 10 & 1 & 5 & 4,26 & Sangat Baik \\
$\begin{array}{l}\text { 3. Ashram Gandhi Puri tetap } \\
\text { menjaga reputasi dengan baik }\end{array}$ & 45 & 39 & 10 & 3 & 3 & 4,2 & Sangat Baik \\
\hline Rata-Rata Skor citra positif organisasi & & & & & & & \\
\hline
\end{tabular}

Berdasarkan tabel di atas didapatkan data bahwa rata rata jawaban responden dalam penelitian ini adalah 4,15 sehingga dapat disimpukan bahwa responden memiliki tanggapan yang baik mengenai citra positif organisasi. Melihat dari beberapa indicator di atas, maka dapat disimpulkan bahwa persepsi masyarakat terhadap Ashram Gandhi Puri tergolong dalam kriteria baik.

\section{Strategi Marketing Public Relations Ashram \\ Gandhi Puri Sevagram Dalam Mempertahankan Citra Positif Organisasi}

Ashram Gandhi Puri Sevagram sempat diberitakan negatif sehingga citranya terpuruk. Hal ini membuat orang luas mengenal Ashram Gandhi Puri Sevagram dari sisi negatifnya. Orang yang belum pernah mengenal Ashram Gandhi Puri Sevagram sama sekali saat itu langsung tahu dari sisi pemberitaan itu. Sudah menjadi hal yang biasa bahwa berita buruk adalah berita yang menarik bagi masyarakat luas. Orang senang mendengar hal-hal yang buruk terjadi. Berita tersebut secara perlahan dapat diredam oleh Marketing Public Relations Ashram Gandhi Puri Sevagram dengan selalu memberikan informasi mengenai aktifitas di ashram kepada publik melalui media cetak maupun online, sehingga pemahaman negatif tersebut membuat masyarakat ragu, dan dengan upaya yang dilakukan secara terus-menerus, maka mereka akan mulai berbalik mendukung keberadaan Ashram Gandhi Puri Sevagram. Pemberitaan mulai membaik dan keburukan yang di share secara terus-menerus tersebut berbalik menjadi kebaikan.

Strategiyang telah dilakukan oleh Marketing Public Relations Ashram Gandhi Puri Sevagram dalam mempertahankan citra positif organisasi adalah dengan menjalankan fungsi dari Marketing Public Relations berdasarkan pandangan Dan Schedel dan Charles Hoffer tentang adanya empat tingkatan strategi yaitu Enterprise Strategy (strategi respon masyarakat), Corporate Strategy (strategi misi organisasi), Bussines Strategy (strategi merebut pasaran), dan Functional Strategy (Strategi Pendukung). Bentuk dan Kegiatan Marketing Public Relations Ashram Gandhi Puri Sevagram dalam Menjalankan Strateginya untuk Meningkatkan Citra Organisasi dilakukan dengan cara mempromosikan setiap kegiatannya menggunakan teori Integrated Marketing Communication melalui :

1. Event seperti Yoga Massal Surya Namaskar Yadnya, Dharma Ashram Taruna dan seminar atau workshop. 
2. Periklanan melalui media Above The Line (ATL), Below The Line (BTL), Out Of Home dan Digital Marketing.

3. Community Network seperti Yoga Sanstha Institute sebagai wadah komunikasi interaktif bagi para penggiat yoga yang ingin lebih mendalami yoga

Marketing Public Relations Ashram Gandhi Puri Sevagram sudah sangat baik hubungannya dengan masyarakat dalam melakukan kegiatannya, sehingga dapat disimpulkan bahwa ketika Ashram Gandhi Puri Sevagram memberikan pelayanan dengan baik kepada masyarakat, maka masyarakat akan percaya kepada Ashram Gandhi Puri Sevagram dan akan memberikan tanggapan atau citra yang baik pula kepada ashram.

\section{Implikasi Strategi Marketing Public Relations Terhadap Pembangunan Citra Ashram Gandhi Puri Sevagram}

Strategi yang diterapkan oleh Marketing Public Relations Ashram Gandhi Puri Sevagram terhadap citra yang selama ini sempat terpuruk memberikan dampak yang signifikan. Isu yang selama ini sempat membuat nama Ashram Gandhi Puri Sevagram terpuruk secara perlahan mulai pulih. Banyak kolega yang mulai mengkonfirmasi kebenaran berita yang sempat didengarnya miring mengenai Ashram Gandhi Puri Sevagram. Pemberitaan yang sempat membuat citra Ashram Gandhi Puri Sevagram terpuruk tersebut ternyata memberikan dampak yang baik pula bagi ashram dimana Ashram Gandhi Puri Sevagram menjadi lebih dikenal oleh masyarakat luas. Peran Public Relation yang tidak pernah mengenal lelah, mampu membuat keterkenalan Ashram Gandhi Puri Sevagram dari citra negatif berubah menjadi positif di mata masyarakat.

Terkenalnya Ashram Gandhi Puri Sevagram oleh masyarakat, membuat Ashram memperoleh kesempatan untuk melakukan pelayanan kepada masyarakat. Hal ini penting karena Ashram Gandhi Puri Sevagram selama ini kehidupannya banyak di support oleh people to people. Banyak orang yang berkontribusi untuk kehidupan Ashram. Banyak tangan-tangan yang membuat Ashram tetap bisa berlangsung dan sebagai gantinya, ashram berupaya untuk melakukan sesuatu yang bisa juga bermanfaat untuk ashram. Berdasarkan pengamatan langsung yang dilakukan dilapangan, peneliti mendapatkan beberapa kegiatan yang dilakukan oleh Ashram Gandhi Sevagram sebagai bentuk dari kontribusi ashram kepada masyarakat seperti memberikan pelajaran Yoga kepada masyarakat luas dan melakukan diskusi publik yang bermanfaat bagi pengembangan pengetahuan dalam berbagai bidang seperti kehidupan, sosial, politik, strategi ekonomi, praktik sosial Mahatma Gandhi, Vedanta dan yang lainnya. Kontribusi yang telah diberikan Ashram Gandhi Puri Sevagram kepada masyarakat telah membuat banyak orang yang bersimpati kepada ashram sehingga Ashram Gandhi Puri Sevagram mendapatkan banyak bantuan berupa beasiswa dan sembako dari para donatur.

\section{SIMPULAN}

1. Persepsi masyarakat terhadap Ashram Gandhi Puri Sevagram berdasarkan tabel pertama di atas yang dilihat dari beberapa indikator yang dapat mewakili jawaban terhadap persepsi masyarakat mengenai Ashram Gandhi Puri Sevagram hal tersebut antara lain dilihat dari Publikasi, iklan layanan masyarakat, Special Event, Promosi dan Publikasi Program, dan Advetorial (Sponsorship) didapatkan data rata rata jawaban responden dalam penelitian ini adalah 4,08 sehingga tergolong dalam kriteria yang baik. Berdasarkan tabel kedua dilihat dari beberapa indikator yang dapat mewakili jawaban terhadap persepsi masyarakat mengenai Citra Ashram Gandhi Puri Sevagram hal tersebut antara lain dilihat dari kepercayaan terhadap organisasi, integritas organisasi dan 
reputasi organisasi, didapatkan data rata rata jawaban responden dalam penelitian ini adalah 4,15 sehingga tergolong dalam kriteria yang baik.

2. Strategi Marketing Public Relations Ashram Gandhi Puri Sevagram dalam mempertahankan citra positif organisasi adalah dengan menjalankan fungsi dari Marketing Public Relations berdasarkan pandangan Dan Schedel dan Charles Hoffer tentang adanya empat tingkatan strategi yaitu Enterprise Strategy (strategi respon masyarakat), Corporate Strategy (strategi misi organisasi), Bussines Strategy (strategi merebut pasaran), dan Functional Strategy (Strategi Pendukung). Bentuk dan Kegiatan Marketing Public Relations Ashram Gandhi Puri Sevagram dalam Menjalankan Strateginya untuk Meningkatkan Citra Organisasi dilakukan dengan cara mempromosikan setiap kegiatannya, Ashram Gandhi Puri Sevagram menggunakan kombinasi dari komunikasi pemasaran melalui Event, Periklanan dan Community Network

3. Implikasi Strategi Marketing Public Relations terhadap pembangunan citra Ashram Gandhi Puri Sevagram adalah dalam keberhasilan strategi yang diterapkan oleh Marketing Public Relations Ashram Gandhi Puri Sevagram terhadap citra yang selama ini sempat terpuruk memberikan dampak yang signifikan. Isu yang selama ini sempat membuat nama Ashram Gandhi Puri Sevagram terpuruk secara perlahan mulai pulih dan mendapatkan kepercayaan dari banyak pihak. Orang kembali bersimpati dengan aktifitas Ashram sehingga ashram menjadi lebih dikenal oleh masyarakat melalui pelayanan yang diberikan oleh ashram sehingga tidak sedikit dari masyarakat yang berkunjung ke Ashram Gandhi Puri Sevagram memberikan bantuan social seperti beasiswa.

\section{DAFTAR PUSTAKA}

Belch,George E, Belch, Michael A. 2009. Advertising and promotion : An Integrated Marketing Communication Perspective. $8^{\text {th }}$ Edition. New York : McGraw-Hill

Brannan, Tom, 2005, Integrated Marketing Communications (Memadukan upaya PR, iklan dan promosi untuk membangun merek) Penerbit : Jakarta, PT.PPM

Jefkins, Frank, 1992, Public Relations, edisi ke 5, Jakarta, Penerbit : PT, Erlangga

Kartono dan Gulo (1987). Kamus Psikologi. Bandung: Pionir Jaya

Setiadi, N.J. 2003. Perilaku Konsumen : Konsep dan Implikasi Untuk Strategi dan Penelitian Pemasaran. Jakarta : Kencana.

Shimp, T.A. 2010, Advertising, promotion, \& other aspects of Integrated Marketing Communication, 8th Edition, SouthWestern, Cengage Learning. 